\title{
An assessment of the implementation of the Early Reading Initiative (ERI) of the Zimbabwean Primary school: A Case Study of the Bumburwi cluster Gweru District.
}

\author{
Thondhlana Saiden (DPhil) \\ Senior Lecturer Educational Studies \\ Zimbabwe Open University \\ Thondhlana Raramai \\ Senior Teacher Chikumbiro Primary School. \\ Cluster resource Person ERI Bumburwi cluster.
}

\begin{abstract}
The Early Reading Initiative (ERI) in Zimbabwean primary Schools was necessitated by early learning gaps that negatively affect performance at grade 7 and 0 level in Zimbabwe which is attributed to incompetency in reading by learners inherited from early grades. Reading competency is a fundamental skill which should be systematically organised for learners to master the necessary pre-reading skills during early learning grades and throughout the primary school years. Zimbabwe is presently implementing a Science Technology Engineering and Mathematics curriculum reading ability is crucial to the implementation of this curriculum. The study was aimed at establishing the implementation of the components of the ERI programme. The study was necessitated by need to establish implementation problem areas so that corrective actions could be undertaken. The sample consisted of Early Childhood Development teachers 7 (ECD), 6 grade one teachers and 5 grade 2 teachers who were purposively chosen. A qualitative paradigm was adopted. A case study design was employed. Lesson observations, in- depth interviews and documents analysis were undertaken. The major findings were that components for the programme were appropriate, most of the components were not excellently implemented and the amount of support given to teachers in the implementation of the programme was quite adequate. Some of the recommendations were that, individual components without fidelity of implementation were to be attended to through staff development sessions, individual teachers with specific problems in implementing certain components to be identified as individual assistance is to be offered to them at school or cluster level.
\end{abstract}

Key Words: Early reading Initiative Components, Component implementation, Zimbabwean primary schools

\section{INTRODUCTION}

Since 2015 Zimbabwean education system has adopted a new curriculum. This curriculum is duped as the Science Technology Engineering and Mathematics curriculum (STEM). For any new curriculum to be implemented successfully reading ability is critical. Reading competency is a fundamental skill which should be systematically organized for learners to master the necessary pre-reading skills during early grades and throughout the primary school years. The teaching was observed by a multiplicity of researchers to be diminishing over the years in Zimbabwe hence the need for intervention strategies to address this crisis at the early learning grades. (Ministry of Primary and Secondary Education, Early Reading Initiative Teachers' Module Grade 2, 2015 P.3). 
Early learning gaps that negatively affect performance at grade 7 and ' 0 ' Level in Zimbabwe are attributed to incompetency in reading by learners that would have been inherited from early grades (Ministry of Primary and Secondary Education, Early Reading Initiative (ERI) Teachers' Module ECD, 2015 p.4). the annual examinations pass rates in Zimbabwe have constantly remained low hence the need to close this gap strengthening the human resource by capacitating the infant teacher with effective early reading teaching skills has become paramount. Hence the introduction of ERI in the education system.

The Government of Zimbabwe received \$23,6 million from the Global Partnership for Education (GPE) for priority educational activities as reflected in the Education Medium Team Plan (2014 - 2016) of the Ministry of Primary and Secondary Education. The funds were for three years namely 2014 - 2016) mainly to support teacher optimization in key areas. UNICEF managed the grant for ministry of primary and secondary Education. The GDE supported the following components, professional Development for better teaching and learning, supervision and management of teacher performance and development and development of education sects strategies Plan for Zimbabwe (2016 - 2020).

The ERI was identified as a component on Professional development for better teaching and learning. The ERI was intended to capacitate the infant school teacher with competencies for effective teaching of reading and writing skills for children from ECD A to Grade 2. A series of staff development sessions were held with infant teachers to equip them - with ERI skills. Not any assessment of implementation of the ERI to the Knowledge of the researcher has been undertaken. The researcher was spurred by this fact to undertake an assessment of the implementation of the ERI programme.

\section{Statement of the problem}

There is a problem of early learning gaps that negatively affect performance at Grade 7 and 0 Level in Zimbabwe attributed to incompetency in reading by learners that would have been inherited from early grade. T address this problem ERI was introduced in the education system in Zimbabwe. No study that the researcher knows of has been carried out on the fidelity of implementation of the ERI. The main research question of this study was

How are the components of the ERI being implemented and what support is needed for fidelity of implementation of the programme?

\section{Sub research questions}

The sub research questions that guided this study were;

- What are the components and variations of implementation of the ERI programme?

- To what extent are the components of the ERI being implemented with fidelity?

- What are the support mechanisms that could ensure fidelity of implementation of the ERI programme?

\section{Purpose of the study}

The study was aimed at establishing the ERI components and how well they were implemented by the infant teachers and support needed to ensure fidelity of implementation

\section{Significance of the study}

The study was intended to make ERI initiators to establish ERI components that were not being implemented well so that teachers could be staff developed in those areas to end up with fidelity of implementation. 
It was also intended to make children to be able to read early ensuring effective reading leading to good performance.

The country would benefit in that if there was success of the STEM Curriculum this was most likely to lead to economic development.

The schools and the Ministry of Primary and Secondary Education would identify the support needed leading to taking of corrective measures.

\section{Delimitations of the study}

The study was delimited to the Bumburwi cluster of the Gweru district and it focused on the implementation of the components of the ERI programme.

\section{Limitations}

The study was a case study so the data collected could not be generalised for the whole district and country because the study was confined to one cluster.

\section{Review of related literature}

The review of related literature will explore the concepts implementation and Early Reading initiative, the theoretical framework of the study and an empirical review of related literature on early reading initiatives.

\section{Implementation}

Implementation is the process of putting into practice an idea, programme or set of activities which is new to the people attempting to bring about a change (Fullan, 1983 p.216 cited in Taylor, 1988b). Bringing about change does not occur " $\ldots$ at a point in time as a result of some sort of profound decision, legislative act or cataclysmic event" (Rutherford, Hall and Hulling, 1983 p.33) it is a process and not an event. The process of implementation of a new educational practice takes time and moves through a series of phases.

If the institutional setting within which implementation takes place is at the national or regional level implementation consists of the execution of policy by an authority so as to influence local delivery organizations to behave in desired ways.

Berman (1987 p. 164) refers to this as macro - implementation and identifies the following chain of four passengers in this process: Administration (an authoritative policy decision leads to a government programme); adoption (the government programme leads to the adoption at a local level). Micro - implementation (the local project leads to an implemented practice); and technical validity (the implemented practice leads to outcomes). Implementation of the ERI programme is at micro - implementation phase that is where the adopted new programme leads to an implemented practice in a school.

The implementation of a new programme or curriculum at local or micro level is brought about by the individuals (Mugweni, 2012) citing Hall, Wallace and Dosett, 1973). Hall, Wallace and Dossett (1973) identify three key variables namely stages of concern, levels of use and innovation configurations. Stages of concern pertain to feelings, perceptions, motivations and attitudes which individuals experience in connection with the use of an innovation (Mugweni, 2012). Levels of use describe individual behaviors as they experience and implement curriculum change (Mugweni, 2012). Innovation configurations spell out what the new programme or practices will look like when it is operation (Hall and Hord, 2001). This study focused on innovation configurations 
Leithwood (1982 p.10) defines implementation as a process of behavioural change in directions suggested by an innovation". The fundamental idea behind this conceptualization of implementation is growth in an individual user (teacher and pupil) and organization. This growth is slow and gradual moving from one stage to the next as obstacles are overcome. In the case of teachers according to Tayor (1988b) these obstacles are lack of knowledge and skill required, negative feelings about an innovation and its implementation, the unavailability of particular resources and the nature of the existing organization of classroom and schools. Lethwood, et., al (1987) the propose curriculum dimensions where growth can occur with respect to teachers' activities when a new programme is introduced. These are goals/ images; objectives; content; teaching strategies, instructional materials and resources; assessment tools and procedures and classroom management. This study also focused on support and the curriculum dimensions pointed out above.

Wang, Noja, Strom and Walberg (1984) conceptualize implementation as the presence or absence of critical programme dimensions in classrooms. This categories of critical programme dimensions have been identified namely dimensions related to the provision of a new programme in the classroom and dimensions related to management and resource supports required to establish and maintain effective implementation. Each of the critical dimensions is characterized by a group or cluster of specific performance indicators. These have been identified through systematic analysis of a programme's structural and action domain. The extent to which the performance indicators for a given dimension are present or in place provides an index of the degree of implementation of that dimension. This study also focused on some of these issues of the ERI .

\section{THE EARLY READING INITIATIVE (ERI)}

Learning to read is seen as a fundamental right for children in a rehanging world (Roskos, Strickland, Haase and Malik, 2009). To achieve at a school and succeed in the world at large children need to know how to read and write. Children should end up as critical readers and writers by participating fully in Literacy.

The early reading initiative as aimed at capacitating children early in their education with reading skills which forms the basis in areas of learning (Ministry of Primary and Secondary Zimbabwe , 2016). The early reading initiative in Zimbabwe is based upon the following reasons, neurological reasons that is the development of the brain, educational reasons that is children have greater knowledge and expand their vocabulary when exposed to early reading activities; psychological reasons that is the early reading initiative promotes a greater maturity and increase discipline; social reasons that is children have the opportunity to relate to their peers on a more confident and competent level and finally for linguistic reasons that is, if exposed to early reading activities children have more opportunities to encounter the written word and end up with the ability to read independently. They end up with improved linguistic skills. In Zimbabwe ERI cutors for ECD, Grade 1 and Grade 2 teachers.

Different countries in the developing world have embraced reading initiatives as chronicled by Roskos et., al. (2009) in the following section.

In Ghana basic education programme activities include an innovative initiative to improve reading comprehension by teaching grade 1 children to read in their local language before making a transition to English. To sustain the programme a cadre of trainers has been established to provide district level training to teachers. 
In Malawi the Primary School support programme (PSSP) is developing a literacy programme that takes a balanced literacy approach. One that combines direct instruction with opportunities for pupils to engage in a variety of print - rich learning experiences. PSSP is conducting focused training for standards one and two teachers designed to help them develop improved skills for teaching reading. PSSP is working with teachers, students and community members to develop supplementary reading materials and reading clubs.

In South Africa the learning for Living Project directed by the READ Educational Trust, Demonstrates the effectiveness of a book-based intervention on students' achievement in more than 1000 rural South African Primary Schools. The READ approach to teacher learning emphasizes on - site, school based support for implementation.

Indonesia a renowned sesame street television show provides $21^{\text {st }}$ Century programming for young children. This provides millions of Indonesian children with first steps in learning to read and in Latin America and Caribbean Region the Centers for Excellence in Teacher Training (CETT) has introduced a more child-centered, interactive approach to the teaching of literacy. To date 15000 teachers in 15 countries have received CETT training. CETT being aided by scholastic books has made libraries of children's books available in classrooms.

\section{THE THEORATICAL FRAMEWORK OF THE STUDY.}

The study has been premised on the Concern Based Adoption Model (CBAM) (Loucks, 1983). The CBAM is explained to describe how individuals undergo the change process. This model arises from research of Fuller (1969) into student teachers concern about teaching. The diagnostic component of the CBAM is described in terms of three dimensions namely stages of concern (the feelings of individuals involved in change); levels of use (how individuals interact with a new programme) and innovation configurations ( how the programme itself is adapted). Roberts (2015) posits that the CBAM has five assumptions about change namely;

- Change is a process, not an event

- Change is accomplished by individuals not institutions. Understanding the change process in organizations requires an understanding of what happens to the individuals as they are involved in change.

- Change is a highly personal experience.

- Change involves development growth in terms of feelings and skill in using the innovation.

- Facilitating change requires focusing on individuals, innovations and the route through the use of information about the change process collected on an ongoing basis.

The study is centered on innovation configurations Hord, Stigelbauer, Hall and George (2006) define innovation configurations as the ideal in terms of the new innovations, strategy or programme and a variety and diversity of new individuals may implement it. Innovation configurations are therefore operational forms of the innovation that result from implementation by different individuals in different contexts. An innovation configuration map is constructed which refers different ways of getting from point A to point B. An innovation configuration map describes different possible operational forms for an innovation. The innovation configuration map identifies the different components of an innovation and variations in the ways each can be implemented.

Hord et al (2006) contend that IC can be used to assess the extent to which the treatment is truly absent from the control group and test the extent to which hypothesized best practices that are stated in state standard do in fact lead to increases in outcomes. IC can answer questions such as whether the innovation has been fully implemented, what the innovation 
looks like more years after adoption, what relationship the innovation has to student outcomes and can provide a baseline for assessing further needs or for responding to funding sources and for developing professional development activities. IC in relation to outcome evaluation can be used to determine the degree to which different configurations are linked to student outcomes.

Hord et al (2006) outline 2 steps to be taken in the construction of an innovation configuration map (IC) map. Step1 entails asking developers for innovation components, asking facilitator for innovation components and developing a list of components, dimensions and variations. Step 2 entails interviewing a small number of users, observing a small number of users and adjusting and expanding the list of components, dimensions and variations. Step3 entails coming up with a draft IC map, interviewing developer, referring to components and variation in draft and developing questions to use with a large sample of people implementing the innovations. Step4 that is the final step involves interviewing and observing a range of users and constructing a semifinal checklist, checking with the innovation experts and making final revisions.

The model also emphasize facilitative actions as support to implementation. The support include some of the following; Staff development sessions, supply of resources, newsletters, cluster resource persons and an examplar school where implementation is carried out with integrity or fidelity.

\section{EMPIRICAL LITERATURE REVIEW}

In trying to come up with ideal components for an Early Reading Initiative programme there is need to review literature on effective strategies that could help children get rid of reading difficulties. The National Academy of Sciences (2018) posits six strategies for grade1to 3 namely for training in phonological awareness, literacy tutoring, reading recovery, book buddies, reading one- one and computer support for reading instruction.

Phonological awareness is the appreciation of speech sounds without regard for their meaning (National Academy Of Sciences, 2018 p.248). This is critical to discovering the alphabetic principle the idea that letters generally represent the small speech segments called phonemes. Phonological awareness training has been found through studies in reading ability. The National Academy of Sciences (2018) cites studies on the effects of phonological awareness one including a sample of 431 children who had not yet received formal reading instruction, 99 had been designated as at risk on the basis of a screening battery. Half of the at risk group received individual tutoring in phonological awareness for a total of about 10 to 15 hours over a 20 week period, during which time regular classroom reading instruction also commenced for all participants. Prior to training there was a substantial difference of 13 to 14 points between mean standard scores of the not-at-risk children and each at-risk group on word identification measure. After the training period, the large gap remained for untrained at-risk group, but the trained group's post-test mean was 7 points below that of the controls who were not-at-risk.

Literacy tutoring is the provision of extra time in reading instruction by tutoring children individually. Reading recovery involves gathering information about the child's literacy strategies and knowledge and includes:

a) Engaging the child in reading previously read books.

b) Independent reading of the book introduced during previous lesson during which the teacher takes a running reward to assess fluency.

c) Letter identification exercises if necessary 
d) Writing and reading his or her own sentences hearing which the child's attention is called to hearing the sounds in words.

e) Reassembling the child's sentence which is not cut up into individual words.

f) Introduction to a new book, and

g) Supported reading of the new book.

The activities occur in a 30 minute block of time on a daily basis. Much time is given to reading familiar books.

Book buddies are a supplementary intervention in which selected children receive one-on-one tutorials twice a week in addition to classroom reading instruction, using highly qualified community volunteers as tutors (Invernizzi et all, 1977 cited in National Academy of Sciences, 2018). The tutors receive continuous on-site training and supervision in the delivery of a fourstep lesson design by reading specialists.

Reading one-on-one uses trained and managed para professionals (college students, community residents and teacher aides to deliver three to five one-on-one tutorial sessions to low performing readers on a weekly basis throughout the school year.

Computer support for reading instructions are another strategy of supporting reading. Children read the material being shown how to do it. Rom programs are being used and story book software are used.

Roskos et al (2009) enumerate the following challenges of teaching reading well in developing countries, language diversity, limited resources, class size, being fed adequately equity no services for special needs learners and limited preparation to teach of the teachers. The teacher leaves college with limited knowledge and skills in teaching. The condition pointed out above, impact negatively on the implementation of the early reading initiative programmes.

Roskos et al (2009)point out that learning to read involves the development of reading skills and strategies that promote independence there is therefore need for the teacher to employ active teaching elements. Roskos et al (2009) enumerate the following teaching elements and their descriptions namely enthusiasm, positive learning environment challenging and appropriate content, responsive instruction, student engagement, variety, assessment for learning and active language arts.

Enthusiasm simply being energetic, interactions and dynamic activity while positive learning environment imply clean, safe and learning focused environment.

Challenging or appropriate content imply evidence based while responsive instruction imply organized, interactive and adaptive work. Student engagement refers to active, respectful and being learning focused while variety imply use of a range of methods and resources.

Assessment of learning need to be ongoing, authentic and useful while active language arts imply attending to reading, writing, speaking and listening.

In coming up with the lesson observation components and general observation components of ERI there was need to consider the above issues on active teaching elements.

Roskos et al (2009) also points out principles of early grades reading which informs on components of the ERI. There are eight of these principles namely Oral language is the 
foundation of learning to read and write; books and texts are varied in genre and form, they are plentiful. The learning environment contains abundant prints of many kinds; an evidencebased curriculum guides reading instruction; teachers are prepared to teach the reading programme well; an assessment system is in place; family involvement and that evaluation is a tool for change. The above principles determine what to generally observe for and what could be in ERI reading lessons.

Roskos et al (2009) reveals eight active learning classroom indicators. These are large supply of books reflecting a variety of topics or genres a classroom library with ample space for 4-5 children and an ample supply of books, print rich environment that includes displays of student work, a daily schedule that allows ample time for reading instruction and independent reading; reading activities that address established literacy content standards and instruction and assessment that focus on key concepts and skills for reading success.

To add to the above are two other issues which include evaluation of students performance based on known criteria, standards and models and active engagement of all students in reading. The indicators lead to components of the ERI programme.

The facilitative assistance or support given to implementation have been pointed out by Taylor (19886) citing Taylor (1987b) and Vanden Berg and Vandenberge(1984). These include the principal as change agent in a change effort, development of local cadres, supply of materials, peer multiplier approach, turnkey trainers, resource centres, demonstration sites, clusters and networks. . Continuous monitoring and evaluation of those implementing any innovation is therefore of paramount importance ( Durrant and Holden, 2006).

Hord and Hall (1984) referring to game plan component level interventions state the following interventions as appropriate; developing appropriate organisational arrangements, training in workshops, modeling and demonstrating, providing consultation and reinforcement, monitoring and evaluation, external communication and developing a public relations campaign.

\section{RESEARCH METHODOLOGY}

\section{Research Design}

The study used the qualitative research paradigm. The study adopted the case study design. This was an intrinsic case study where no attempt was made to generalize the single case or even to build theories (Silverman, 2010).

\section{Data generation instruments}

The instruments used for data generation were the observation, checklist and document analysis checklists. Also open ended questionnaires or questerviews were employed. Open ended interview questions were also used. The above instruments were used following the advice by Ford et al (2006) that establishment of IC should be obtained through direct observation and open ended interviews.

\section{Selection of participants and information}

The Bumburwi cluster has a total of 45 teachers. The sample of teachers constituted of 7 early childhood and development (ECD) teachers, 6 grade 1 teachers and 5 grade 2 teachers who were purposively selected. These were teachers who volunteered to be observed and be interviewed. In every school at least one teacher was picked for the ECD, grade 1 and grade 2 
respectively. The sample therefore consisted of 18 teachers. The sample also included the schools inspector responsible for ERI.

\section{DATA COLLECTION PROCEDURES}

At first permission was sought from the Ministry of Primary and Secondary Education. After Permission was granted the researcher who is the ERI cluster resource person and this researcher studied ERI modules to identify the component, the schools' inspectors responsible for ERI was interviewed to identify the IC components. The steps documented in the empirical Literature review section for $1 \mathrm{C}$ components identification was followed. Having established the component and variations the ERI cluster resource teacher observed lessons. Some lesson observations were narratively reposted yet some used the $1 \mathrm{C}$ map items. The soles were subjected to open ended questionnaires and interviews regarding support rendered toward implementation. A study of minutes of cluster meetings was also undertaken.

\section{Data Analysis Procedures}

The researchers followed Merriam's (2009) analysis of qualitative data. The other data from checklists was analysed from the tables and emerging trends were noted.

\section{FINDINGS OF THE STUDY}

The finding of this study are presented in four parts. The first part is a report of narrative reports on lesson observations made by the cluster resource in various schools in the cluster. No real names of schools were used but schools are referred to as school A and so on. The third part are findings on checklists on components and variations on general observations and lesson observations undertaken by the cluster resource person ERI. The fourth part constitute comments of the ERI programme from the teachers in the cluster while the last part deals with the support given to the teachers in relation to the implementation of the ERI programme.

\section{Established components and variations of ERI programme}

A content review of modules, an interview with the schools inspector responsible for ERI and a review of related Literature on early reading revealed the following components with regards general observation entail reading record which promote different skills, letter knowledge, vocabulary fluency speaking and comprehension resourcefulness of the teacher, library corner story books language centre, colourful charts, children learning trough play way, giving work according to ability grouping, collection of nursery rhyme books, phonics activities, sentence making with new words, sentence to give skill to the meaning of the word, essence of summarising read stories in a good diagram, reading in other curriculum subjects, picture reading, reading at home and non-readers. The variations are A excellent, existence $B$ satisfactory existence, $C$ little existence and D none existence.

The lesson observation components entail child friendly atmosphere introduction of rhymes, new words activities done for example nursery rhymes, games to help achieve objective, predicting amend to a story, use of gestured/ non- verbal communication activities relating to what children experience use of visual media promoting creatures understanding providing regular praise, comprehension on work done, group activities, group work reposting as a class and not to teacher only, encourage correct use of language and talk in ways that catch learners attention. The variations are the same as for the general observations noted above.

\section{Narrative reports on lesson observations by the ERI cluster resource person}

The narrative reported issues are presented school by school. One lesson was observed for ECD, grade 1 and grade 2. At school A at ECD level the report indicated the need to use media that can be used by the whole class instead of a few pupils, the need to have more activities to 
master left to right orientation, need to have many play way activities since children learn through play way need to record the activities or skills in reading need to use one language in a single sentence and need to have a library corner.

The grade 1 lesson seen at school A was a renumber activities lessons. It was noted that simple language was well used and media used was suitable, pupils were involved recording was not done and there was no library corner and non-use picture books, the left to right once nation was emphasised ad material learnt was put in diagrams showing depth of understanding assessment was carried out and non-verbal communication was used.

The grade 2 lesson seen at school A was on colours. The following issues were noted, media was used, there was emphasis on left to right orientation, fine motor skills were developed by handing objects familiar media was used, the playway method was employed, there was encouragement of further communication through further activities, the record book had only a list of names but did not have any information recorded on child performance, speaking made slow learners to be confident, the teacher used both shona and English in line with the ministry policy, need to refer to things that children like from home and there is need for involvement of all pupils at school B at ECD level a lesson of visual skills was observed. The following points were noted, teacher instructions clear, there was use of song that the teacher sang with children, activities and mastery of material was recorded, pointing out parts missing could have been done, children were supposed to pay attention, there were appropriate pictures on walls, there was need for the ECD class were maintained.

At school B at grade 1 level a lesson on oral language development was observed. The following issues were noted, recall was emphasised, the reader listened to all pupils as they spoke, the teacher also talked with pupils, the sitting arrangement was quite appropriate and there was use of music interludes.

At school B at grade 2 level a lesson on reading fluency was observed, The following issues were pointed out, the new words were used in sentences, the teacher helped children in pronouncing words, the teacher had only records for the week, pupils were attentive but there is a need to increase group word questions for only one was made, story reading followed a need to use pictures to summarise a story, the use of nonverbal (gestures) was evident children had to be encouraged to bring items from home to beef up what was available. Emphasis on phonics was not apparent, every lesson was to be a reading lesson and assessment needed to be done.

At school $\mathrm{C}$ a lesson for ECD on expressive language was observed. The following issues were noted, need for interpreting different sounds, introduction included sound with actions, expressing thought, instruments with different sounds were used in a mystery box was used and children named instruments that produced the sound while hidden, a child friendly atmosphere obtained, children were actively involved and enjoyed the lesson and the seven play centres were available.

At school C grade 2 levels was observed. The following points were noted, there was use of fingers to demonstrate left to right orientation, performance by activities was recorded but there was need for more pupil activity. Activities were to be done in a play way fashion.

At school D at ECD level a lesson nonverbal messages and symbols was seen. The following issues were pointed out; activities were appropriate, children were actively involved in showing movements and means of non- verbal communications, facial expressions showing 
mood were used, a reading record with different skills is kept, all 7 corners were present and a variety of charts to aid in reading and learning were used.

At school D at grade 1 level a comprehension lesson was observed, The following issues were noted, Appropriate use of word cards, the use the actual garden and vegetables like carrots, covo etc. that was in line with the comprehension passage, new words had their meanings cleared, there was a chorus reading to help the slow ones, there was need to emphasize more of nonverbal communication and need to cater for individual differences and use of poems and rhymes to help children.

At the same school the grade 2 lesson was on English reading- pronouncing words correctly. The following points were noted, the use of objects in line with the words, children were encouraged to communicate in L2, words were stuck just as posed to objects, there imitation of sounds and related words and repetition of words, recording was up to date, the lesson was inter chided with rhymes, there was no book corner and language centre and group work was employed and made to be actively involved. There is however need to draw up a list of all that have been covered in a record book and record if children are able to read them.

\section{THE INNOVATION CONFIGURATION COMPONENTS THEIR VARIATIONS AND POTRAYAL OF EXTENT OF IMPLEMENTATION OF THE ERI PROGRAMME.}

Table 1 below shows information on innovation configuration map, components and variation for general observation for ECD.

Table 1: Innovation Configuration Map: Components and variations; General observations Early Childhood Development ( ECD) (N=7)

Key: A: Excellent Existence

B: Satisfactory Existence

C: Little Existence

D: None Existence

\begin{tabular}{|c|c|c|c|c|c|c|c|c|}
\hline \multirow[t]{2}{*}{ Components } & \multicolumn{8}{|c|}{ Variations } \\
\hline & A & & B & & $\mathrm{C}$ & & $\mathrm{D}$ & \\
\hline 1.Reading record which promotes different skills, letter & $\mathrm{N}$ & $\%$ & $\mathrm{~N}$ & $\%$ & $\mathrm{~N}$ & $\%$ & $\mathrm{~N}$ & $\%$ \\
\hline $\begin{array}{l}\text { knowledge, vocabulary, fluency speaking and } \\
\text { comprehension. }\end{array}$ & 4 & 57 & 3 & 43 & 0 & 0 & 0 & 0 \\
\hline 2.Resourcefulness of teacher & 7 & 100 & 0 & 0 & 0 & 0 & 0 & 0 \\
\hline 3.Library corner & 5 & 71 & 2 & 29 & 0 & 0 & 0 & 0 \\
\hline 4.Story books & 6 & 86 & 1 & 14 & 0 & 0 & 0 & 0 \\
\hline 5.Language centre & 5 & 71 & 2 & 29 & 0 & 0 & 0 & 0 \\
\hline 6.Colourful charts & 7 & 100 & 0 & 0 & 0 & 0 & 0 & 0 \\
\hline 7.Children learning through playway & 4 & 57 & 3 & 43 & 0 & 0 & 0 & 0 \\
\hline 8.Giving work according to ability grouping & 2 & 29 & 5 & 71 & 0 & 0 & 0 & 0 \\
\hline 9.Collection of nursery rhyoric books & 3 & 43 & 2 & 29 & 2 & 29 & 0 & 0 \\
\hline 10.Phonic activities & 1 & 14 & 3 & 43 & 2 & 29 & 1 & 14 \\
\hline $\begin{array}{l}\text { 11.Sentence making with new words, sentence to give } \\
\text { clue to the meaning of the word }\end{array}$ & 2 & 29 & 3 & 43 & 1 & 14 & 1 & 14 \\
\hline $\begin{array}{l}\text { 12.Evidence of summarizing read stories in a good } \\
\text { diagram. }\end{array}$ & 0 & 0 & 6 & 86 & 1 & 14 & 0 & 0 \\
\hline 13.Reading in other curriculum subjects & 2 & 29 & 3 & 43 & 1 & 14 & 1 & 14 \\
\hline 14.Picture reading & 5 & 71 & 1 & $\overline{14}$ & 1 & 14 & 0 & 0 \\
\hline 15.Reading at home & 3 & 43 & 3 & 43 & 1 & 14 & 0 & 0 \\
\hline 16.Non-readers & 0 & 0 & 1 & 14 & 3 & 43 & 3 & 43 \\
\hline
\end{tabular}


Below Table 1 above reveal that $(n=4) 57 \%$ and $(n=3) 43 \%$ of the teacher have excellent existence and satisfactory existence of the component reading record which promoted different skill, letter knowledge vocabulary, fluency speaking and comprehension respectively.

One hundred percent $100 \% \quad(n=7)$ of the teachers exhibited excellent existence of resourcefulness. Seventy one percent $71 \%(n=5)$ of the teacher and $(n=2) 29 \%$ of the teachers exhibited existence and satisfactory existence of the component library corner respectively. Eighty six percent $86 \%(n=6)$ and $(n=1) 14 \%$ of the teachers exhibited excellent existence and satisfactory existence of the component story books respectively. Seventy one percent $(n=5)$ and $29 \%(n=2)$ of the teachers exhibited excellent existence and satisfactory existence in the component language centre respectively. One hundred percent $(n=7)$ of the component colourful charts respectively. Fifty seven percent $57 \%(n=4)$ and $(n=3) 43 \%$ of the teachers exhibited excellent existence and satisfactory existence of the component children learning through play way respectively.

Twenty nine percent $29 \%(n=2)$ and $(n=5) 71 \%$ of the teachers exhibited excellent existence and satisfactory existence of the component giving work according to ability grouping respectively. Forty three percent $43 \%(n=3),(n=2) 29 \%$ and $(n=2) 29 \%$ of the teachers exhibited excellent existence, satisfactory existence and little existence of the component collection of nursery rhyme books respectively. Fourteen percent $14 \%(n=1),(n=3) 43 \%$, $(n=2) 29 \%(n=1)$ exhibited excellent existence, little existence and none existence of the component phonics activities respectively. Twenty nine percent $29 \%(n=2),(n=3) 43 \%,(n=1)$ $14 \%$ and $(n=1) 14 \%$ of the teachers exhibited excellent existence of the component sentence, making with new words, sentence to give clue to the meaning of the word respectively. Eighty six percent $86 \%(n=6)$ and $(n=1) 14 \%$ of the teachers exhibited satisfactory existence and little existence of the component evidence of summarising the read stories in a good diagram respectively. Twenty nine percent $29 \%(n=2),(n=3) 43 \%,(n=1) 14 \%$ and $(n=1) 14 \%$ of the teachers exhibited the component reading in other curriculum subjects respectively. Seventy one percent $71 \%(n=5),(n=1) 14 \%$ and $(n=1) 14 \%$ of the teachers exhibited the component picture reading respectively. Forty three percent $43 \%(n=3),(n=3) 43 \%$ and $(n=1) 14 \%$ of the teachers reflected the excellent existence satisfactory existence and little existence of the component reading at home and $(n=1) \quad 14 \%(n=3) 43 \%$ and $(n=3) 43 \%$ of the teachers revealed the extent of non-reader component in the range of satisfactory existence, little existence and nonexistence respectively.

Table 2 below shows the innovation configuration showing component and variation for ECD lesson observation. 
Table 2: An Innovation Configuration Map showing components and variations for ECD Lesson Observation. $\mathrm{N}=7$.

Key: A: Excellent Existence

B: Satisfactory Existence

C: Little Existence

D: None Existence

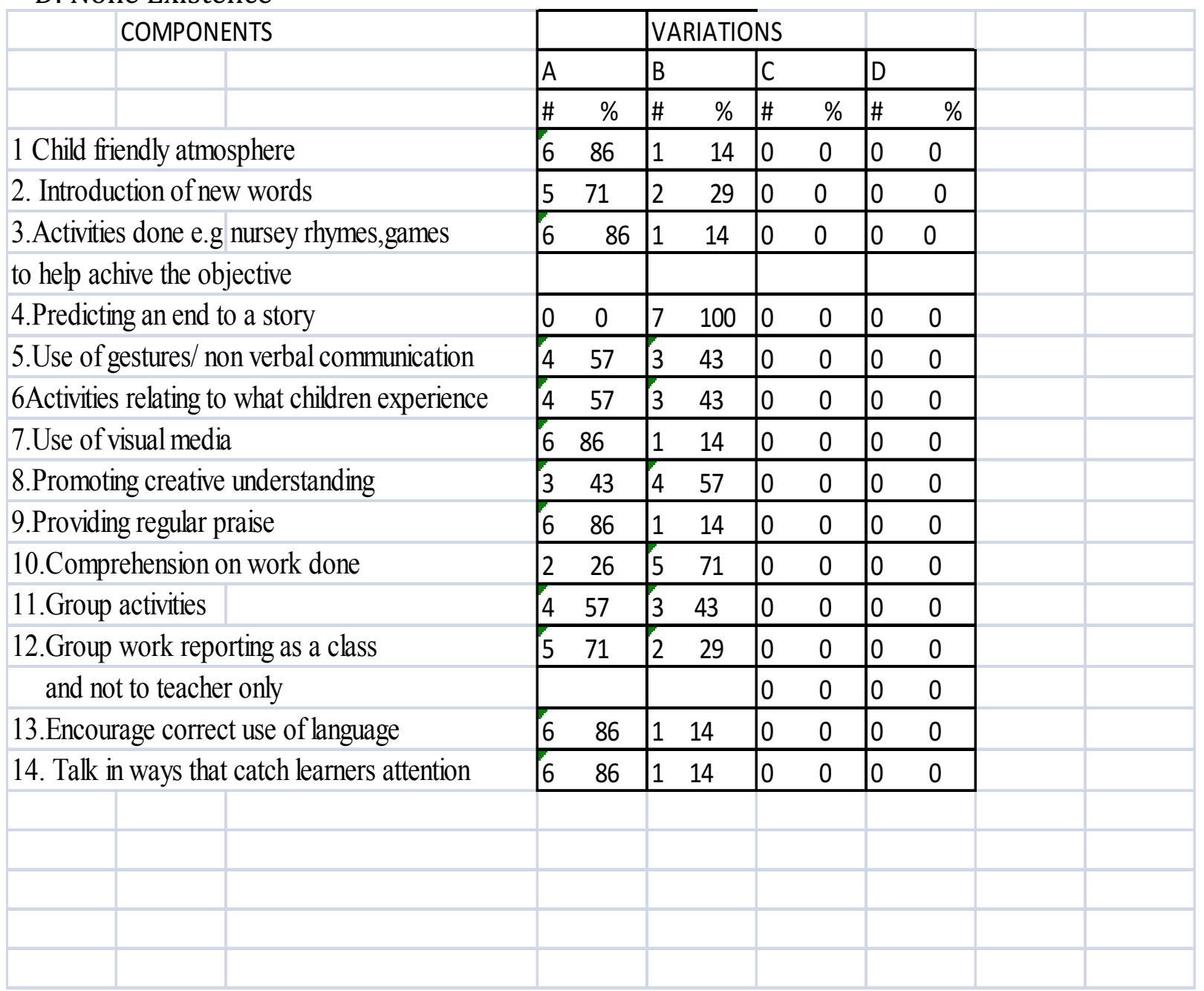

Table 2 reveals that $(n=6) 86 \%$ and $(n=1) 14 \%$ of the teachers exhibited excellent existence and satisfactory existence of the component child friendly atmosphere respectively. Seventy one percent $71 \%(n=5)$ and $(n=2) 29 \%$ of the teachers exhibited excellent existence and satisfactory existence of the component introduction of new words respectively. Eighty six percent $86 \%(n=6)$ and $(n=1) 14 \%$ of the teachers exhibited excellent existence and satisfactory existence of the component activities done for example nursery rhymes, games to help achieve the objective respectively.

One hundred percent $100 \%(n=7)$ of the teachers exhibited satisfactory existence of the component predicting an end to story. Fifty seven percent $57 \%(n=4)$ and $(n=3) 43 \%$ of the teachers exhibited excellent existence and satisfactory existence of the component use of gestures/ nonverbal communication respectively.

Fifty seven percent $57 \%(n=4)$ and $(n=3) 43 \%$ of the teachers exhibited excellent existence and satisfactory existence of the component activities relating to what children experience respectively. 
Eighty six percentage $86 \%(n=6)$ and $(n=1) 14 \%$ of the teachers exhibited excellent existence and satisfactory existence of the component of use of visual mafia respectively.

Forty three percent $43 \%(n=3)$ and $(n=4) 57 \%$ of the teachers exhibited excellent existence and satisfactory existence of the component promoting creative understanding respectively.

Eighty six percent $86 \%(n=6)$ and $(n=1) 14 \%$ of the teachers exhibited excellent existence and satisfactory existence of the component providing regular praise respectively.

Twenty six percent $26 \%(n=2)$ and $(n=5) 41 \%$ of the teachers exhibited excellent existence and satisfactory existence of the component comprehension on work done respectively.

Fifty seven percent $57 \%(n=4)$ and $(n=3) 43 \%$ of the teachers exhibited excellent existence and satisfactory existence of the component group activities respectively.

Seventy one percent $71 \%(n=5)$ and $(n=2) 29 \%$ of the teachers exhibited excellent existence and satisfactory existence of the component group work reporting as a class and not to the teacher only.

Eighty six $86 \%(n=6)$ and $(n=1) 14 \%$ of the teachers exhibited excellent existence and satisfactory existence of the component encouraging correct use of language while $(n=6) 86 \%$ and $(n=1) 14 \%$ of the teachers exhibited excellent existence and satisfactory existence of the component talking in ways that catch the learners' attention.

Table 3 shows innovation configuration components and variations for general observations for Grade 1. 
Saiden, T., \& Raramai, T. (2018). An assessment of the implementation of the Early Reading Initiative (ERI) of the Zimbabwean Primary school: A Case Study of the Bumburwi cluster Gweru District. Advances in Social Sciences Research Journal, 5(6) 602-625.

Table 3 Innovation Configuration Map; Components and variations: General observations Grade $1(\mathrm{~N}=6)$

Key A: Excellent existence,

B: Satisfactory existence,

C: Little existence

D: Non existence

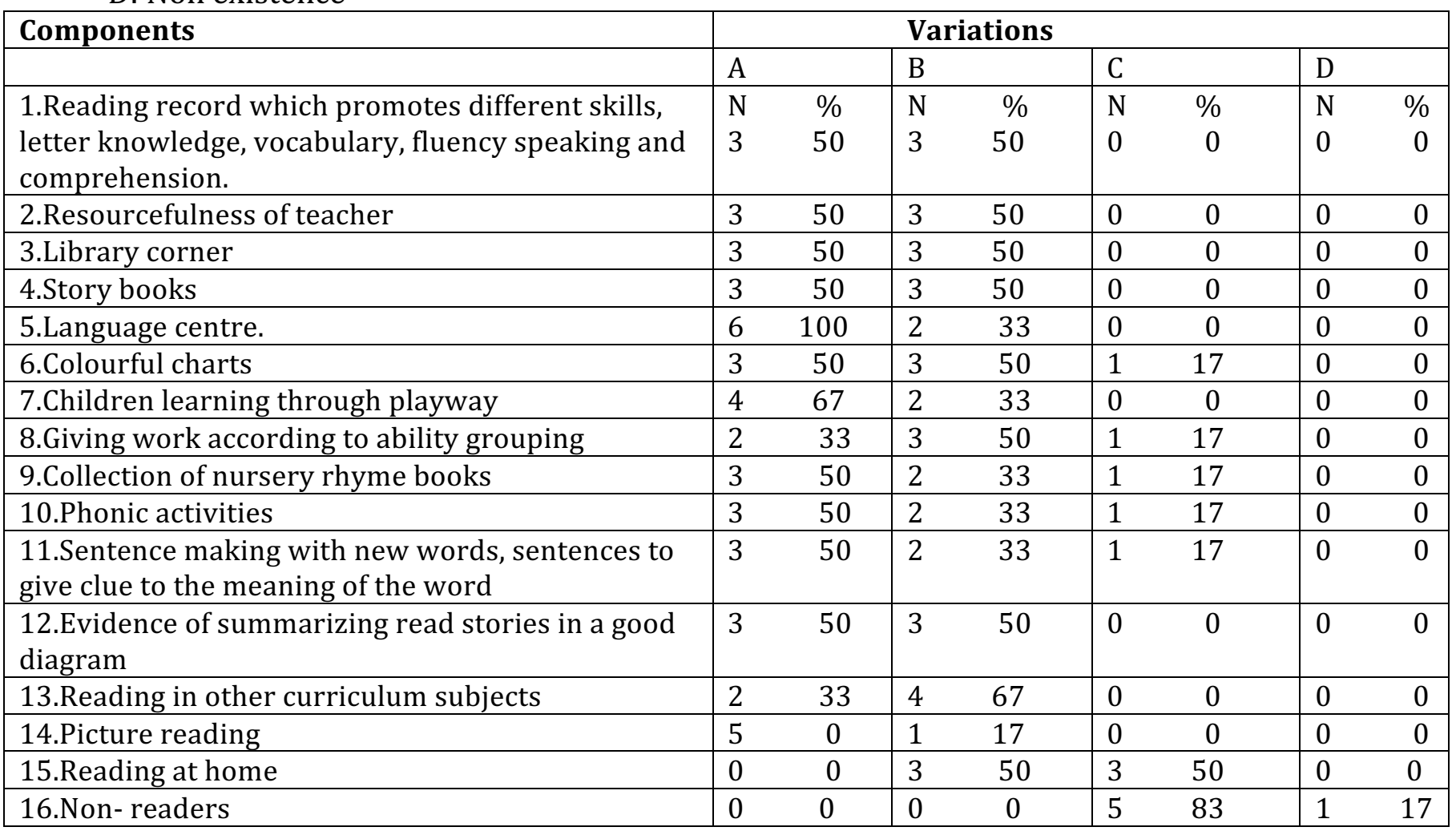

Table 3 reveals that $(n=3) 50 \%$ and $(n=3) 50 \%$ of the teachers exhibited excellent existence and satisfactory existence of the component reading record which promotes different skills, letter knowledge, vocabulary, fluent speaking and comprehension respectively. Fifty percent $50 \%(n=3)$ and $(n=3) 50 \%$ of the teachers exhibited excellent existence and satisfactory existence of the component resourcefulness respectively. Fifty percent $50 \%(n=3)$ and $(n=3)$ $50 \%$ of the teachers exhibited excellent existence and satisfactory existence of the component library corner respectively. Fifty percent $50 \%(n=3)$ and $(n=3) 50 \%$ of the teachers exhibited excellent existence and satisfactory existence of the component story books respectively. One hundred percent $100 \%(n=6)$ of the teachers exhibited excellent existence of the component language centre respectively. Fifty percent $50 \%(n=3)$ and $(n=3) 50 \%$ of the teachers exhibited excellent existence and satisfactory existence of the component story books. One hundred percent $100 \%(n=6)$ of the teachers exhibited excellent existence of the component language centre. Fifty percent $50 \%(n=3)$ and $(n=3) 50 \%$ of the teachers exhibited excellent existence and satisfactory existence of the component colourful charts respectively. Sixty seven percent $67 \%(n=40,(n=1)$ and $(n=1)$ of the teachers exhibited excellent existence, satisfactory existence and little existence of the component children learning through play way. Sixty seven $67 \%(n=4),(n=1) 17 \%$ and $(n=1) 17 \%$ of the teachers exhibited excellent existence, satisfactory existence and little existence of the component giving work according to ability grouping. Thirty three $33 \%(n=2),(n=3) 50 \%$ and $(n=1) 17 \%$ of the teachers exhibited excellent existence, satisfactory existence and little existence of the component collection of nursery books. Thirty three percent $33 \%(n=2),(n=2) 33 \%,(n=1) 17 \%$ and $(n=1) 17 \%$ of the teachers exhibited excellent existence, satisfactory existence, little existence and none existence of the component phonics activities. Thirty three percent $33 \%(n=2),(n=3) 50 \%$ and 
$(n=1) 17 \%$ of the teachers exhibited excellent existence, satisfactory existence and none existence of the component sentence making with new words and sentence to give clue to the meaning of the word. Fifty percent $50 \%(n=3),(n=1) 17 \%$ and $(n=2) 33 \%$ of the teachers exhibited excellent existence, satisfactory existence and little existence of the component evidence of summarizing read stories in a good diagram. Thirty three percent $33 \%(\mathrm{n}=2)$, $(n=3) 50 \%$ and $N=1) 17 \%$ of the teachers exhibited excellent existence, satisfactory existence and none existence of the component reading in other curriculum subjects. Thirty three percent $33 \%(n=2),(n=1) 17 \%$ and $(n=3) 50 \%$ of the teachers exhibited excellent existence, satisfactory existence and little existence of the picture reading component. Fifty percent 50\% $(n=3)$ and $(n=3) 50 \%$ of the teachers exhibited satisfactory existence and little existence of the component reading at home while $(n=5) 83 \%$ and $(n=1) 17 \%$ of the teacher revealed little existence and none existence of the component non readers.

Table 4 shows the innovation configuration components and variations for Grade 1 lesson observations.

Table 4 innovation configuration map; components and variations for Grade 1: lesson observation $(\mathrm{N}=6)$

Key A: Excellent existence,

B: Satisfactory existence,

C: little existence

D: Non existence

\begin{tabular}{|c|c|c|c|c|c|c|c|c|}
\hline \multirow[t]{2}{*}{ Components } & \multicolumn{8}{|c|}{ Variations } \\
\hline & A & & B & & $\mathrm{C}$ & & $\mathrm{D}$ & \\
\hline \multirow{2}{*}{ 1.Child friendly atmosphere } & $\mathrm{N}$ & $\%$ & $\mathrm{~N}$ & $\%$ & $\mathrm{~N}$ & $\%$ & $\mathrm{~N}$ & $\%$ \\
\hline & 6 & 100 & 0 & 0 & 0 & 0 & 0 & 0 \\
\hline 2.Introduction of new words & 4 & 67 & 2 & 33 & 0 & 0 & 0 & 0 \\
\hline $\begin{array}{l}\text { 3.Activities done e.g nursery rhymes, games to help } \\
\text { achieve the objective }\end{array}$ & 4 & 67 & 2 & 33 & 0 & 0 & 0 & 0 \\
\hline 4.Predicting an end to a story & 0 & 0 & 6 & 100 & 0 & 0 & 0 & 0 \\
\hline 5.Use of gestures / non - verbal communication. & 4 & 67 & 2 & 33 & 0 & 0 & 0 & 0 \\
\hline 6.Activities relating to what children experience & 2 & 33 & 3 & 50 & 1 & 17 & 0 & 0 \\
\hline 7.Use of visual media & 4 & 67 & 2 & 33 & 0 & 0 & 0 & 0 \\
\hline 8.Promoting creative understanding & 2 & 33 & 3 & 50 & 1 & 17 & 0 & 0 \\
\hline 9.Providing regular praise & 3 & 50 & 2 & 33 & 1 & 17 & 0 & 0 \\
\hline 10.Comprehension on work done & 3 & 50 & 2 & 33 & 1 & 17 & 0 & 0 \\
\hline 11.Group activities & 3 & 50 & 2 & 33 & 1 & 17 & 0 & 0 \\
\hline $\begin{array}{l}\text { 12.Group work reporting as a class and not to } \\
\text { teacher only }\end{array}$ & 3 & 50 & 3 & 50 & 0 & 0 & 0 & 0 \\
\hline 13.Encourage correct use of language & 2 & 33 & 4 & 67 & 0 & 0 & 0 & 0 \\
\hline 14.Talk in ways that catch learner's attention. & 5 & 83 & 1 & 17 & 0 & 0 & 0 & 0 \\
\hline
\end{tabular}

Table 4 reveals that $(n=6) 100 \%$ of the teachers exhibited excellent existence of the component child friendly atmosphere. Sixty seven percent $67 \%(n=4)$ and $(n=2) 33 \%$ of the teachers exhibited excellent existence and satisfactory existence of the component introduction of new words respectively. Sixty seven percent $67 \%(n=4)$ and $(n=2) 33 \%$ of the teachers exhibited excellent existence and satisfactory existence of the component activities done for example nursery rhymes, games to help achieve the objective respectively. One hundred percent $100 \%$ $(n=6)$ of the teachers exhibited excellent existence of the component predicting the end of a story. Sixty seven percent $67 \%(n=4)$ and $(n=2) 33 \%$ of the teachers exhibited excellent existence and satisfactory existence of the component use of gestures/ none verbal 
communication respectively. Thirty three percent $33 \%(n=2),(n=3) 50 \%$ and $(n=1) 17 \%$ of the teachers exhibited excellent existence, satisfactory existence and little existence respectively of the component activities relating to what children experience. Sixty seven percent $67 \%(n=4)$ and $(n=2) 33 \%$ of the teachers exhibited excellent existence and satisfactory existence of the component use of visual media respectively. Thirty three percent $33 \%(n=2),(n=3) 50 \%$ and $(n=1) 17 \%$ of the teachers exhibited excellent existence, satisfactory existence and little existence of the component promoting creative understanding respectively. Fifty percent $50 \%(n=3),(n=2) 33 \%$ and $(n=1) 17 \%$ of the teachers exhibited excellent existence, satisfactory existence and little existence of the component proving regular praise respectively. Fifty percent $50 \%(n=3),(n=2) 33 \%$ and $(n=1) 17 \%$ of the teachers exhibited excellent existence, satisfactory existence and little existence of the component comprehension on work respectively. Fifty percent $50 \%(n=3),(n=2) 33 \%$ and $(n=1) 17 \%$ of the teachers exhibited they employed group work excellently, satisfactorily and little. Fifty percent $50 \%(n=3)$ and $(n=3) 50 \%$ of the teachers exhibited excellent existence and satisfactory existence of the component group work reporting as a class and not to the teacher only respectively. Thirty three percent 33\% $(n=2)$ and $(n=4) 67 \%$ of the teachers exhibited excellent and satisfactory existence of the component encouraging correct use of language and yet $(n=5) 83 \%$ and $(n=1) 17 \%$ of the teachers exhibited excellent and satisfactory existence of the component talking in ways that catch learners attention.

Table 5 below shows innovation configuration components and variations for the general observations for Grade 2. 
Table 5: Innovation Configuration Map: Components and Variations: General Observations Grade 2

Key: A: Excellent Existence

B: Satisfactory Existence

C: Little Existence

D: None Existence

\begin{tabular}{|l|ll|l|l|l|l|l|}
\hline Components & \multicolumn{2}{l}{ Variations } & & & \\
\hline \\
$\begin{array}{l}\text { 1.Reading record which promotes } \\
\text { different skills, letter knowledge, } \\
\text { vocabulary, fluent speaking and } \\
\text { comprehension. }\end{array}$
\end{tabular}

Table 5 above reveals $(n=1) 20 \%$ and $(n=4) 80 \%$ of the teachers exhibited excellent existence and satisfactory existence of the component reading record which promotes different skills, letter knowledge, vocabulary, fluent speaking and comprehension respectively. One hundred percent $100 \%(n=5)$ of the teachers exhibited excellent existence of the component resourcefulness of the teacher. One hundred percent $100 \%(n=5)$ of the teachers exhibited excellent existence of the component library corner. Sixty percent $60 \%(n=3)$ and $(n=2) 40 \%$ of the teachers exhibited satisfactory existence and little existence of the component story books. Twenty percent $20 \%(n=1),(n=1) 20 \%$ and $(n=3) 60 \%$ of the teachers exhibited excellent, satisfactory and little existence of the component language centre respectively. One hundred percent $100 \%(n=5)$ of the teachers exhibited excellent existence of the component colourful charts. Sixty percent $60 \%(n=3)$ and $(n=2) 40 \%$ of the teachers exhibited excellent and satisfactory existence of the component children learning through play way. One hundred percent $100 \%(n=5)$ of the teachers exhibited excellent existence of the component giving work according to ability grouping. Twenty percent $20 \%(n=1)$ and $(n=4) 80 \%$ of the teachers exhibited excellent and satisfactory existence of the component collection of nursery rhyme books respectively. Eighty percent $80 \%(n=4)$ and $(n=1) 20 \%$ of the teachers exhibited excellent and satisfactory existence of the component phonics activities. Eighty percent $80 \%$ $(n=4)$ and $(n=1) 20 \%$ of the teachers exhibited excellent and satisfactory existence of the component sentence making with new words, sentences to give clue to the meaning of the word respectively. One hundred percent 100\% $(n=4)$ of the teachers exhibited satisfactory existence of the component evidence of summarizing read stories in a good diagramme. Eighty 
percent $80 \%(n=4)$ and $(n=1) 20 \%$ of the teachers exhibited excellent and little existence of the component reading in other curriculum subjects. One hundred percent $100 \%(n=5)$ of the teachers exhibited excellent existence of the component picture reading. Twenty percent $20 \%$ $(n=1),(n=3) 60 \%$ and $(n=1) 20 \%$ of the teachers exhibited,excellent, satisfactory and little existence of the component reading at home while $20 \%(n=1)$ and $(n=4) 80 \%$ of the teachers exhibited satisfactory and little existence of the component none readers.

Table 6 shows innovation configuration components and variations for lesson observation for Grade 2 Classes.

Table 6: Innovation configuration Map: Components and Variations: Lesson Observation Grade 2

Key: A: Excellent Existence $(\mathrm{N}=5)$.

B: Satisfactory Existence

C: Little Existence

D: None Existence

\begin{tabular}{|c|c|c|c|c|c|c|c|c|}
\hline \multirow{3}{*}{\begin{tabular}{|l|} 
Components \\
1 Child friendly atmosnhere
\end{tabular}} & \multicolumn{2}{|c|}{ Variations } & & & \\
\hline & A & & B & & $\mathrm{C}$ & & $\mathrm{D}$ & \\
\hline & $\mathrm{N}$ & $\%$ & $\mathrm{~N}$ & $\%$ & $\mathrm{~N}$ & $\%$ & $\mathrm{~N}$ & $\%$ \\
\hline & 5 & 100 & 0 & 0 & 0 & 0 & 0 & 0 \\
\hline 2.Introduction of new words. & 5 & 100 & 0 & 0 & 0 & 0 & 0 & 0 \\
\hline $\begin{array}{l}\text { 3.Activities done eg nursery rhymes, game to help } \\
\text { achieve the objective. }\end{array}$ & 3 & 60 & 2 & 40 & 0 & 0 & 0 & 0 \\
\hline 4.Predicting an end to a story. & 0 & 0 & 5 & 100 & 0 & 0 & 0 & 0 \\
\hline 5.Use of gestures/ non-verbal communication. & 4 & 80 & 1 & 20 & 0 & 0 & 0 & 0 \\
\hline 6.Acitivities relating to what children experience. & 4 & 80 & 1 & 20 & 0 & 0 & 0 & 0 \\
\hline 7.Use of visual media. & 5 & 100 & 0 & 0 & 0 & 0 & 0 & 0 \\
\hline 8.Promoting creative understanding. & 3 & 60 & 2 & 40 & 0 & 0 & 0 & 0 \\
\hline 9.Providing regular praise. & 4 & 80 & 1 & 20 & 0 & 0 & 0 & 0 \\
\hline 10.Comprehension on work done. & 3 & 60 & 2 & 40 & 0 & 0 & 0 & 0 \\
\hline 11.Group activities. & 1 & 20 & 4 & 80 & 0 & 0 & 0 & 0 \\
\hline $\begin{array}{l}\text { 12. Group work reporting as a class and not to the } \\
\text { teacher only. }\end{array}$ & 1 & 20 & 4 & 80 & 0 & 0 & 0 & 0 \\
\hline 13.Encouraging correct use of language. & 3 & 60 & 2 & 40 & 0 & 0 & 0 & 0 \\
\hline 14.Talk in ways that catch learners' attention & 1 & 20 & 4 & 80 & 0 & 0 & 0 & 0 \\
\hline
\end{tabular}

Table 6 reveals $(n=5) 100 \%$ of the teachers exhibited excellent existence of the component child friendly atmosphere. One hundred percent $100 \%(n=5)$ of the teachers exhibited excellent existence of the component introduction of new words. Sixty percent $60 \%(n=3)$ and $(n=2) 40 \%$ of the teachers exhibited excellent and satisfactory existence of the component activities done for example nursery rhymes, games to help achieve the objective. One hundred percent $100 \%(n=5)$ of the teachers exhibited satisfactory existence of the component predicting an end of the story. Eighty percent $80 \%(n=4)$ and $(n=1) 20 \%$ of the teachers exhibited excellent and satisfactory existence of the component use of gestures/ non verbal communication respectively. Eighty percent $80 \%(n=4)$ and $(n=1) 20 \%$ of the teachers exhibited excellent and satisfactory existence of the component activities relating to what children experience. One hundred $100 \%(n=5)$ of the teachers exhibited excellent existence of the component use of visual media. Sixty percent $60 \%(n=3)$ and $(n=2) 40 \%$ of the teachers exhibited excellent and satisfactory existence of the component promoting creative understanding respectively. Eighty percent $80 \%(n=4)$ and $(n=2) 20 \%$ of the teachers 
exhibited excellent and satisfactory existence of the component providing regular praise. Sixty percent $60 \%(n=3)$ and $(n=2) 40 \%$ of the teachers exhibited excellent and satisfactory existence of the component comprehension on work done respectively. Twenty percent $20 \%$ $(n=1)$ and $(n=4) 80 \%$ of the teachers exhibited excellent and satisfactory existence of the component group activities. Twenty percent $20 \%(n=1)$ and $(n=4) 80 \%$ of the teachers exhibited excellent and satisfactory existence of the component group work reporting as a class and not to the teacher only respectively. Sixty percent $60 \%(=3)$ and $(n=2) 40 \%$ of the teachers exhibited excellent and satisfactory existence of the component encouraging correct use of language while $(n=1) 20 \%$ and $(n=4) 80 \%$ of the teachers exhibited excellent and satisfactory existence of the component talking in ways that catch learners' attention.

\section{SUPPORT GIVEN TO TEACHERS IN RELATION TO ERI IMPLEMENTATION}

Support is given in the form of professional staff development sessions that are held regularly at cluster level to assess progress in the implementation of the programme where problematic areas are noted and resolved. At school level after the cluster meetings meetings are held to report back on what was pointed out at the cluster meeting by representatives. In attendance at the cluster sessions are representatives from each school for ECD, Grade 1 and Grade 2. Heads of schools and Teachers in Charge of infant teachers also attend the cluster sessions.

The support in terms of material provision include; ERI modules for ECD, Grade 1 and Grade 2 for every teacher. A variety of story books are also provided for each class though there are only limited copies to go round every child. Children are encouraged to bring story books from home which they share. They are also encouraged to write own short stories they share with members of the class. Teachers also write short stories read by children. Copies of nursery rhymes are made available to teachers. The nursery rhyme copies need to be beefed up and teachers need to create own nursery rhymes.

The cluster resource person for ERI makes periodic visitations to each teacher in the cluster and these include lesson observations and component implementation assessment. At school the heads and Teachers in Charge supervise the implementation of the ERI programme. School level teachers in charge of ERI also do lesson observations and attend to problems encountered by the teachers in their schools.

\section{General comments on ERI ECD}

\section{GENERAL COMMENTS ON ERI}

The teachers expressed the following sentiments about the ERI programme at ECD level;

- Programme that equips pupils with reading skills at their sensitive period.

- It is good since most children are boasting confidence through engaging in different activities,

- It is a better way of improving language and reading skills,

- Chidren learn language and improve vocabulary.

How to improve the programme

The ECD teachers expressed the following on how to improve the prograamme;

- More refresher courses to be held,

- Proving adequate material for children to learn.

- More time needed so teacers to be exempted from activities such as sports,

- Removing of extra records.

Number of none readers

The number of readers were as follows: $0,0,2,0,0,0$ and 0 . 


\section{General comments Grade 1}

The following were comments about the ERI from the Grade 1 teachers;

- A good programme,

- Let it continue; schools to provide enough resources for it to be effective,

- It is a boring programme.

How to improve the programme at Grade 1 level.

The following sentiments were expressed;

- Schools to provide resources, the teacher needs to be resourceful in order to have some activities relating to what pupils experience,

- Providing adequate modules for teachers.

None readers

The following were none readers in Grade 1 classes;10, 13, 8, 4, 10 and nil.

General comments for Grade 2.

The following were the general comments from the Grade 2 teachers about the ERI;

- It has to be implemented,

- The programme is to continue,

- A good programme that assists learners to read fluently,

- It is a good programme that promotes reading in pupils.

How to improve the programme

The following issues were pointed out on how to improve the programme;

- By providing audio visual materials,

- More staff development programmes.

None readers

The none readers in the Grade 2 classes were as follows; 8, 12, 10, 11 and 13.

\section{DISCUSSION OF THE FINDINGS}

The components that were identified for the general observations namely reading records which promoted different skills, letter knowledge, vocabulary, fluency speaking and comprehension, resourcefulness of the teacher, library corner, story book, language centre, colourful charts, children learning through play way, giving work according to ability, grouping, collection of nursery rhyme books, phonic activities, sentence making with new words, sentence to give clue to the meaning of the word evidence of summarising read stories in a good diagram, reading in the curriculum subjects picture reading, reading at home and non-readers and lesson observation components of child friendly atmosphere, introduction of new words, activities done. For example nursery rhymes, games to help achieve the objectives predicting an end to a story, use of gestures/ non-verbal communication activities relating to what children experience, use of visual media promoting creative understanding, providing regular praise comprehension on work done, group activities, group work reposting as a class and not the teacher one, encouraging correct use of language and talking in ways that catch learners attention all corroborate strategies to be used in helping the children with reading difficulties advanced by the National Academy of science (2018). They also corroborate active teaching elements advanced by Rockos el al (2009) principles of early reading classroom indicators advanced again by Roskos (2009). What this implies is that if the components are effectively attended to they might see the early reading programme through.

Lesson observations for narrative writing purposes reflect the ECD Lesson at school did not have media activities/skills in reading, use of one language in a single sentence and no library 
corner. The grade at a school lesson exhibited no recording of reading skills, no library corner and no use of picture books abs lessons observation at grade 2 at school an exhibited non maintenance of record for reading skills and both languages were used. All other aspects handled. The record keeping component is conspicuously absent throughout.

At school B lesson observation for narrative repost writing reflected the ECD lesson should have the pointing out of parts mussing that pupils should be attentive and need for activity to keep children active. All other aspects were well handled. The grade 1 lesson reflected that all aspects were well handled. The grade 2 lesson reflected pupils ought to be helped in pronouncing group work word questions should be increased. Use of pictures to summarise a story, emphasis of phonics not apparent, assessment not done and children to bring items from home to beef up those in the class. All other were well handled.

At school $\mathrm{C}$ lesson observations for narrative report writing reflected the ECD lesson has all aspects attend to. The grade 1 lesson reflected no language centre need for use of fingers to demonstrate left to right orientation need to train in phonics, no pre-formal timetable and need to record pre-formal learning skills acquisition. The grade 2 lesson reflected every aspect was well handled.

At school D lesson observation for narrative report writing reflected the ECD lesson showed everything was well handled. The grade 1 lesson reflected that more non- verbal communications had to be used and more poems and rhymes could help. Everything else was alright. The grade 2 lesson reflected there were no library corner, no language corner and no emphasis on phonics. Everything else was well handled. The lesson observation report throughout the schools did not however point out the extent of existence.

The handling at the innovation components ought to consider integrity or fidelity of implementation. Integrity or fidelity of implementation requires teachers to be operating at excellent existence level anything below this means a shortfall.

At ECD level the components colourful charts seems to be the only components that is implemented with fidelity on the general observation component and predicting an end to a story on the lesson observation components. This implies that the other components have to be attended to. Teachers who are not operating at excellent existence level need to be identified and staff development undertaken on them.

At grade 1 level only the component colourful charts is implemented with fidelity of implementation on the general observation components. All the lesson observation components have to attend to. Teachers who are falling short in these areas need to be identified and staff developed so that they reach the excellent existence level. At grade 2 level only the general observation components of resourcefulness of a teacher, colourful charts and giving work according to ability grouping evidence of summarising read story is a good diagram are implemented with fidelity. The picture reading best need to be attended to with regards to the lesson observation components. With regards lesson observation components the following are implemented with fidelity, child friendly atmosphere, introduction of new words, predicting on end to a story and use of usual media, the rest are not. Teachers who are lagging behind ought to be identified and be afforded the necessary staff development.

The facilitative assistance or support given to implementation of ERI concurs with those pointed out by Taylor (19886) citing Taylor (1987b) and Vanden Berg and Vandenberge(1984). These include the principal as change agent in a change effort, 
development of local cadres and networks. The support not offered in the implementation of ERI programme is that of documentation and information centres that are exemplar schools where the change is being implemented with fidelity and the technical support systems for example a clearing house a place and procedures to prepare a newsletter.

\section{CONCLUSIONS}

From the above findings the following conclusions can be drawn:

- ERI components have been drawn out well.

- The implementation of the ERI components requires facilitation in the majority of component

- Appropriate facilitative assistance is being offered to the teachers except in only two areas

\section{RECOMMENDATIONS}

The following recommendations can be proferred:

- Individual components without fidelity of implementation to be attended to through staff development sessions

- Individual teachers with specific problems in certain component implementation to be identified and individual assistance to be given either at school level or by the cluster resource teachers.

- Further research could be undertaken to establish the Stage of Concern of the teachers regarding ERI and the Levels of Use regarding ERI.

\section{References}

Durrant, T. \& Holden, G. (2006) Teachers Leading Change: Doing Research for School Improvement. London: Paul Chapman publishers.

Fullan,M (1983).Evaluating Program Implementation: What can be learned from follow through. Curriculum Inquiry 13(2) p.217-219.

Hall G.E. and Locks S.F. (1981). Analysing what change Facilitators do the interventions taxotomy. Knowledge creation, Diffusion utilisation (8) p.275-292

Hall, GE,Dirksen D J and George, A.A (2006). Measuring the implementation in schools: level of use. University of Texas at Austin: Research and Development Centre for Teacher Education

https://www.air.org/sites/default/files/CBAM levels of use of pdf acceesed 02/01/2018

Hord S.M., Rutherford W.L, Hulling Austin L. and Hall G. E. (1987). Talking of Change, Washington D C: Association for supervision and curriculum development

Hord, S M, Stigebauer,S M, Hall, G.E. and George, A.A. (2006). Measuring Implementaion in Schools: Innovation Configurations. SEDL Mueller, Blod Austin. ISBN 978-0-9777208-2-8

Leithwood K.A. (1982). Studies in Curriculum Decision Making. Toronto:/SE press

Leithwood,K.A. and Montgomery, D, J (1987). Improving classroom practice. Using innovation profiles. Toronto: The Ontarian Institute for studies in Education.

Merriam, S. B. (2009). Qualitative Research: A Guide Design and Implementation, San Francisco: Jossey Bass

Ministry of Primary and Secondary Education (2015). Early reading Initiative Teachers Module ECD. Harare Curriculum Development Unit.

Ministry of Primary and Secondary Education (2015). Early Reading Initiative Teachers Module Grade 2. Harare: Curriculum Development Unit.

Mugweni, R. (2012) Secondary school teacher conceptualisation and implementation of the Aids Action Programme in Zimbabwe. Unpublished PhD Thesis, Pretoria: University of Pretoria.

National Academy of sciences (2018) Helping children with reading difficulties in grade 1-3. Preventing Reading Difficulties in young children, Washington, DC: National Academy of sciences 
Roberts K. (2015) Theories of change: Concerns based Adoption model. Global Education Sunmmit @ USAID Education accessed 24/11/17

Roskos, K., Strickland, D., Haase, J. and Maliki, S. (2009). First Principles for Early Grades Reading Programs in Developing Countries. New York: Reading Association in American Institutes for Research.

Rutherford, W.K., Hall, G.E. and Hulling, L.L. (1983). Implementing Instructional Change: The Concern Based Perspective. Teacher Inquiry, 3(5) p.133-143.

Silverman, D. (2010). Doing Qualitative Research: A practical Handbook. London: Sage

Taylor,C.A. (1986). The evaluation of curriculum implementation in schools with special reference to gifted education, unpublished report to the Human sciences Research Council. South Africa.

Van den Berg, R. (1981). Large Scale Strategies For Supporting Complex Innovations in participating Schools. General Report of a conference at Hetogenbosch, The Netherlands: Kathohek Padagogisch Cetrum:7 p. 46-50.

Wang,M.C. Noja, M. Strom, C.D. and Wcdberg,H.J (1984). The utility of degree of implementation measures on program implementation and Evaluation research. Curriculum Inquiry, 14(3) 